\title{
Diaphragm quantitative electromyography: upgrading an important tool in the search for diaphragmatic myopathy in asthmatic patients
}

\author{
Eletromiografia quantitativa de diafragma: atualizando uma importante ferramenta na \\ busca por miopatia diafragmática em pacientes asmáticos
}

Paulo Jose LORENZONI ${ }^{1}$

\footnotetext{
Universidade Federal do Paraná, Hospital de Clínicas, Departamento de Clínica Médica, Serviço de Neurologia, Serviço de Doenças Neuromusculares, Curitiba PR, Brasil.

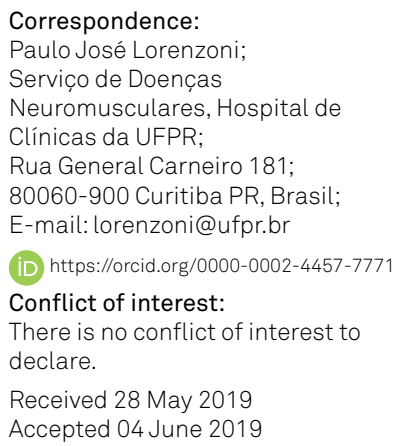

Received 28 May 2019 Accepted 04 June 2019

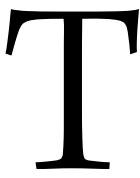

he study of phrenic nerve conduction and needle electromyography (EMG) of the diaphragm can be useful in evaluation of patients with respiratory failure ${ }^{1,2}$. Although other methods have been included in the diaphragm evaluation in recent years (e.g. ultrasound), these electrophysiological methods are able to directly demonstrate the presence of myopathy and neuropathy related to the diaphragm muscle that can contribute to the respiratory failure.

In May 2019, the term 'phrenic' and 'nerve conduction study' was identified in more than 600 articles in the PubMed database. At same time, the term 'diaphragm' and 'needle electromyography' was found in a little over 80 articles in the PubMed database. These findings may suggest that neurologists are more familiar with phrenic nerve conduction studies than needle EMG of the diaphragm. In fact, neurologists should be familiar with both diagnostic tools, as well as being able to recognize the situations in which they may be useful.

The standard qualitative and quantitative methods of EMG analysis of the diaphragm muscle are established ${ }^{3}$. Qualitative EMG is routinely performed and may be sufficient to assess some of the diaphragmatic diseases². Quantitative EMG (QEMG) may help, when the results of qualitative EMG are equivocal or minimal, in the clarification of a possible diaphragmatic disease. Quantitative EMG is a time-consuming technique (mainly the 'manual' analysis), which requires practice and patience but it can be of invaluable diagnostic assistance in selected patients ${ }^{4}$. Quantitative EMG analysis is performed by measuring multiple motor unit action potentials (multi-MUAP), using different methods and software that are able to identify the MUAP parameters 4 . Quantitative EMG parameters can be analyzed by computer-based algorithms ('template-operated' or 'automated') or by 'manual' (visual) measurements ${ }^{4}$.

However, although this field is not novel in the literature, more studies are still needed to establish the feasibility and clinical value of diaphragmatic QEMG for different diseases. Indeed, in the computer-based QEMG of the diaphragm muscle, at least one study was not able to demonstrate its value, possibly due to technical limitations ${ }^{1,5}$.

In this issue of Arquivos de Neuropsiquiatria, Caetano et al. ${ }^{5}$ examined the use of QEMG to investigate diaphragmatic myopathy as a possible intercurrence in difficult-to-treat (severe refractory) asthmatic patients. Their article revealed that QEMG analysis of diaphragm muscle was feasible in difficult-to-treat asthmatic patients. In addition, QEMG analysis was helpful in identifying concomitant myopathic changes in diaphragm muscle of asthmatic patients. This finding may help us understand whether the persistence of respiratory dysfunction in these patients is caused by concomitant diaphragmatic myopathy. In addition, the authors believed that a diaphragmatic myopathy related to corticosteroids may explain their findings in difficult-to-treat asthmatic patients, but further studies should be done to confirm this hypothesis, mainly performing QEMG in other muscles (besides the 
diaphragm) and muscle biopsy. This study upgrades the list of situations for which an EMG of diaphragm muscle is recommended, including a disease associated with obstructive respiratory failure (asthma).

In addition, the Caetano et al..$^{5}$ study innovated by using a software with a longer recording time (30 seconds) in the program of multi-MUAP analysis (computer-based QEMG), which enabled analysis during continuous normal breathing. The computer-based QEMG is usually aimed at studying limb muscles; unfortunately special muscles, such as the diaphragm, could not be put into the same criteria of MUAP acceptance by the standard software programs. The waxing and waning that occur physiologically during breathing and the small MUAPs of the diaphragm muscle are parameters that interfere in the multi-MUAP analysis if the same computer-based QEMG algorithms as the limb muscles are adopted. This upgrade in the QEMG method suggested by Caetano et al. ${ }^{5}$ may help solve one of the technical limitations found in previous studies ${ }^{1,5}$. The article by Caetano et al. ${ }^{5}$ points out that tailored criteria for automated MUAP acceptance should be used to improve the accuracy of the computer-based QEMG in diaphragm muscle.

\section{References}

1. Leonardis L, Podnar S. Template-operated MUP analysis is not accurate in the diagnosis of myopathic or neuropathic changes in the diaphragm. Neurophysiol Clin. 2017 Dec;47(5-6):405-12. https://doi.org/10.1016/j.neucli.2017.07.003

2. Maranhão AA, Rodrigues MM, Carvalho SR, Caetano MR, Compagnoni IM, Carnio TK, et al. Is phrenic nerve conduction affected in patients with difficult-to-treat asthma? Arq Neuropsiquiatr. 2018 Mar;76(3):177-82. https://doi.org/10.1590/0004-282×20180010
3. Podnar S, Resman-Gaspersic A. Quantitative motor unit potential analysis in the diaphragm: a normative study. Muscle Nerve. 2008 Apr;37(4):518-21. https://doi.org/10.1002/mus.20939

4. Nandedkar SD, Stalberg E, Sanders D. Quantitative EMG. In: Dumitru D, Amata AA, Zwarts MJ, editors. Electrodiagnostic Medicine. Philadelphia: Hanley \& Belfus; 2002. p. 296-300.

5. Caetano MR, Maranhão AA, Peixoto EM, Alamy AH, Nucera AP, Rodrigues Filho JC. Diaphragm quantitative electromyography in difficult-to-treat asthmatic patients Arq Neuropsiquiatr. 2019;77(8):550-54. https://doi.org/10.1590/0004-282X20190085 